\title{
Novos negócios fonográficos no Brasil e a intermediação do mercado digital de música'
}

New phonographic busines in Brazil and the intermediation of digital music market

\section{Leonardo De Marchi}

Doutorando no Programa de Pós-Graduação em Comunicação da UFRJ/RJ/BR. leonardodemarchi@gmail.com

Luis Alfonso Albornoz

Professor no Departamento de Jornalismo e Comunicação Audiovisual da UC3M/Madrid/ES. Luisalfonso.albornoz@uc3m.es

Micael Herschmann

Professor no Programa de Pós-Graduação em Comunicação da UFR//RJ/BR. micaelmh@globo.com

\section{RESUMO}

Neste artigo, analisam-se as estratégias de algumas recentes empresas brasileiras que apostam em novas práticas de comercialização de gravações musicais no entorno digital. Afastando-se do modelo tradicional de venda de discos em suporte físico, as empresas aqui analisadas, iMusica, Trevo Digital, Fun Station e Bolacha Discos, buscam novas maneiras de distribuir seus conteúdos musicais através de distintos meios em um mercado fonográfico em plena reformulação. Os casos selecionados revelam que novas formas e graus de mediação entre produtores e consumidores se colocam como elemento importante do emergente mercado digital de fonogramas.

Palavras-chave: comunicação; cultura; indústria fonográfica

\section{ABSTRACT}

This article analyzes the strategies implemented by a handful of Brazilian companies founded over the last decade that have established new practices for marketing and promoting musical recordings in the digital environment. The cases considered here, iMusica, Trevo Digital, Fun Station and Bolacha Discos, are developing innovative content distribution and promotion methods for a record market undergoing a major transformation. The cases selected reveal that new forms and degrees of mediation are emerging as key elements in a fully digitalized music market.

KEYWORDS: communication; culture; record industry 
o longo do século $X X$, os agentes que compõem a indústria fonográfica desenvolveram Auma exitosa estrutura internacional de produção, distribuição, promoção e consumo de música gravada em distintos suportes físicos. Desde o início de seu processo de digitalização, contudo, este ramo das indústrias culturais tem enfrentado sérios problemas para conciliar as novas práticas de distribuição e consumo de fonogramascom a tradicionalestrutura de comércio de música gravada. Por distintas causas, que não serão analisadas aqui, a indústria fonográfica vem registrando quedas contínuas nas vendas de discos e déficit crescente nos balanços de suas principais empresas. Segundo dados da Federação Internacional da Indústria Fonográfica (IFPI, 2010, p. 03), entre 2004 e 2009, o mercado internacional de fonogramas físicos retraiu-se em 30\%.

Em alguns países, a situação é particularmente delicada. Tal é o caso do Brasil. A partir da décadade 1960, o mercado brasileiro de discos se torna internacionalmente expressivo. Para isto, contribuíram vários fatores como o desenvolvimento da televisão comercial; o surgimento de uma nova geração de compositores e intérpretes, que se aglomeraram em "movimentos musicais" (bossa-nova, MPB, jovem-guarda, tropicália); e a transformação da juventude brasileira em público-alvo da indústria de discos (Napolitano, 2001). Durante a década seguinte, as gravadoras multinacionais que operavam no país iniciaram uma vigorosa fase de modernização e expansão de suas estruturas. Importantes investimentos foramfeitos em setores estratégicos como o tecnológico, artistas e repertório, divulgação e marketing (Midani, 2008; Morelli, 2009). Pouco a pouco, tais gravadoras assumiram o domínio do mercado brasileiro de discos, integrando verticalmente as estruturas de produção, distribuição e divulgação (Dias, 2000). Nesse período, as corporações multinacionais também se converteram nos principais agentes responsáveis pela introdução de inovações tecnológicas e comerciais nesse mercado. O intenso processo de crescimento da indústria de discos resultante dessas inovações converteu o mercado fonográfico local em um dos cinco mais rentáveis do mundo, no ano de 1979. Este se caracterizaria por um alto grau de produção e consumo de música local, provida por um oligopólio de gravadoras multinacionais.

A partir dos anos 1990, entretanto, esse contextoinicia um processo de transformação. Entre as novidades mais significativas, podem-se assinalar:

a) aumento da competição entre empresas. Ao final dessa década surge uma nova geração de gravadoras brasileiras independentes - como Trama, Biscoito Fino e Deckdisc - que servem de opção para artistas locais que não encontram espaço nas multinacionais. 
b) crescimento do mercado de reproduções "piratas" de fonogramas. Segundo dados da Associação Anti-Pirataria de Cinema e Música (APCM), o comércio de cópias físicas ilegais de produtos protegidos por leis de direitos autorais correspondia a $48 \%$ do mercado de discos em 2006. A Associação Brasileira de Produtores de Discos (ABPD) afirma em seu site que, entre 1995 e 2007, houve uma redução de 50\% do faturamento do setor fonográfico, na perda de 3.500 postos de trabalho e na diminuição do investimento, sobretudo por parte das gravadoras multinacionais, em torno de $44 \%$, significando uma diminuição de $50 \%$ na contratação de artistas locais.

c) emergência de novas formas de distribuição e consumo de arquivos musicais digitalizados (compartilhamento por peer-to-peer, compra de música por internet ou telefones celulares, entre outros meios). Para se ter uma ideia desse crescimento, segundo a ABPD (2009, p. 6-7), entre 2006 e 2008 o mercado digital de música no Brasil deixou de representar apenas $2 \%$ do mercado, arrecadando 8,5 milhões de reais, para corresponder a $12 \%$, gerando 43,5 milhões ${ }^{2}$.

Enfim, enquanto as grandes gravadoras se encontram em um contexto de maior competitividade empresarial, retração do mercado formal e expansão do informal, além de se mostrarem pouco capazes de explorar as oportunidades econômicas do entorno digital, novos agentes surgem, propondo caminhos alternativos à indústria fonográfica brasileira. São empreendimentos criados levando em consideração a profunda transformação que experimenta o mercado e que, portanto, voltam-se às novas possibilidades de distribuição e consumo de música.

Neste sentido, é plausível sugerir que estes empreendedores e seus novos negócios representem o tipo-ideal do empresário schumpeteriano ${ }^{3}$, ou seja, aquele agente que introduz mudanças em um mercado e encaminha sua reestruturação. No entanto, faz-se necessário saber: quem são estes empreendedores? Que estratégias comerciais desenvolvem? O que apresentam de efetivamente inovador em relação ao modelo tradicional de comércio de fonogramas? O que representa sua existência para o mercado local?

\section{Novos negócios fonográficos no Brasil}

As empresas consideradas neste artigo apresentam novas estratégias de comercialização de conteúdos musicais. Ainda que não sejam as únicas companhias dessa natureza existentes no 
Brasil, iMusica, Trevo Digital, Fun Station e Bolacha Discos formam uma representativa amostra do que ocorre no mercado fonográfico brasileiro neste momento. Sua escolha se justifica por ter na distribuição e venda de fonogramas sua principal atividade; desenvolver novas estratégias de acesso ao mercado consumidor de fonogramas que se distinguem do modelo tradicional; destacarem-se pelacapacidade de explorar as novas possibilidades de comunicação e comércio proporcionadas pelas tecnologias digitais.

Assim, buscou-se realizar uma análise que permitisse estabelecer diferenças e similitudes entre as tendências desenvolvidas. A análise de páginas virtuais das empresas (oferta de catálogo de conteúdos e serviços), a realização de entrevistas pessoais e via telefônica com os responsáveis pelos empreendimentos selecionados ${ }^{4}$ e o estudo da presença dessas empresas em redes sociais (MySpace, Facebook, Twitter, etc.) foram empregados (realizados entre dezembro de 2009 e fevereiro de 2010) para o desenvolvimento do argumento aqui defendido.

\section{iMusica}

Sediada na cidade do Rio de Janeiro, a $i M u s i c a^{5}$ faz parte da holding Ideiasnet S.A., companhia que desenvolve projetos e adquire participações em companhias do setor de tecnologia, mídia e telecomunicações. Criada em 2000, a iMusica foi pioneira em explorar os novos serviços de distribuição de mídia digital legalizada pela internet e pela telefonia celular e, hoje, goza da posição de uma das mais estruturadas empresas dessa natureza na América Latina. Atualmente, a companhia é administrada por Felippe Llerena (ex-fundador e manager de gravadoras independentes como Natasha Records e Nikita Music, além de trabalhar para Biscoito Fino) e Paulo Lima (com experiência em gravadoras brasileiras e multinacionais, em cargos técnicos e administrativos).

Segundo as informações publicadas em seu site, a iMusica contabiliza cerca de dez milhões de usuários cadastrados e um catálogo de mais de dois milhões de fonogramas licenciados por gravadoras nacionais e internacionais. Além disto, mantém acordos com todas as editoras musicais do país e entidades arrecadadoras de direitos autorais na América Latina. No Brasil, é provedor de conteúdo e plataforma distribuidora de música para sites, portais de conteúdo, empresas de bens de consumo e de entretenimento, canais varejistas, operadoras e fabricantes de celulares. Também é um canal de exportação do conteúdo das gravadoras brasileiras independentes para lojas digitais internacionais tais como iTunes, Napster, Amazonmp3, eMusic, Rhapsody, entre outros. 
Atuante no mercado de telefonia celular, a companhia possui contratos tanto com operadoras (Claro, Vivo, Oi, TIM) quanto com uma fabricante (Nokia) para distribuir conteúdo digital - ao todo, serve a 19 operadores de telefonia celular em 16 países da América Latina, com alcance total de mais de 278 milhões de usuários. Possui uma rede de lojas de música na internet em parceria com os grandes portais e sites de e-commerce como MSN Music, Yahoo Music, Rádio Transamérica, Wal-Mart, entre outras. Isto significa que a empresa não apenas possui sua própria loja virtual como também projeta e administra sistemas de venda de conteúdos digitais para terceiros.

AiMusica é uma holding em si, o que lhe permiteatingir distintos tipos de clientes. Para editoras, gravadoras independentes e produtoras de artistas, funciona como distribuidora digital de fonogramas, gestora de direitos de reprodução das obras, distribuição dos direitos autorais e/ou gerenciamento de conteúdo (enconding). Para outro tipo de firmas, interessadas na utilização da música como ferramenta de publicidade, a companhia desenvolve diversos tipos de serviços de publicidade e marketing para mídia digital. Finalmente, para varejistas, portais de internet e operadoras de telefonia celular, provê tecnologia e desenvolve estratégias de distribuição do conteúdo digital. Enfim, há um conjunto de diferentes serviços que são independentes, ainda que possam ser conjugados, gerando rendas próprias que podem ser utilizadas para investimento em uma ou outra parte da empresa.

\section{Trevo Digital}

A Trevo Digital é uma companhia de distribuição e venda online de fonogramas digitais. Com sede em Curitiba, a empresa foi fundada em 2007, pelos músicos Luiz Eduardo Túlio e Eduardo Teixeira com o fim de vender os discos da própria banda. Atualmente, a empresa conta com quatro funcionários (os dois sócios, um programador e um estagiário) e presta serviços para artistas e selos discográficos independentes.

Em seu site, o consumidor pode adquirir fonogramas de um catálogo de 2.000 faixas disponíveis de 200 artistas cadastrados. O sistema de venda da Trevo Digital apresenta uma interessante novidade, a chamada "loja portátil". Artistas ou selos podem armazenar fonogramas em uma central de informações (datacenter) da Trevo Digital, que gera uma janela a qual o artista contratante pode incluir em sua página virtual e/ou em alguma rede social em que disponibilize sua obra. Assim, descentraliza-se a venda dos arquivos, facilitando o acesso do consumidor ao 
produto. A busca pela ampliação potencial do público leva a Trevo Digital a apostar no uso de redes sociais: também a empresa possui uma página em MySpace ${ }^{7}$.

A venda de fonogramas digitais não é sua única renda. Cada artista que contrata os serviços da empresa deve pagar uma anuidade de 30 reais pelo armazenamento e gestão dos arquivos, além da geração e administração da "loja portátil". Além disso, desenvolveu-se em parceira com a empresa paulista Alternetmusic Ltda. a Trevo Box 8 - um serviço especializado em licenciar direitos de reprodução da obra de um artista para distintos fins (uso em cinema, publicidade, programas de televisão, internet, jogos-eletrônicos, etc.). Neste caso, o artista contratante do serviço recebe $50 \%$ do valor da licença, ficando a outra metade com a Trevo Box.

\section{Fun Station}

Fundada em 2008 por três amigos (Bruno De Marchi, Armando Perico e Douglas Silva), a Fun Station $^{9}$ tem sede na cidade de São Paulo. Atualmente, conta com 13 funcionários em sua equipe, tendo a Marcos Maynard (ex-presidente de importantes gravadoras multinacionais, como Polygram, Universal e EMI, além da brasileira Abril Music) como sócio e máximo responsável. A Fun Station fornece a estrutura para venda de conteúdos digitais para grandes gravadoras (atualmente, a empresa desenvolve uma parceria com a Warner Music), gravadoras independentes e artistas autônomos. Atualmente, seu catálogo apresenta cerca de 300.000 arquivos e as máquinas se encontram em lojas como FNAC, Carrefour e Jet Music dos estados do Rio de Janeiro (2), São Paulo (9), Rio Grande do Sul (1), Amazônia (1), Piauí (4), Maranhão (1), além de duas instalações no exterior, em Miami e Santiago do Chile.

A empresa se destaca por haver desenvolvido uma tecnologia definida como "posto de abastecimento digital". Trata-se de um computador exposto em lojas ou lugares públicos através da qual o consumidor acessa a diferentes tipos de conteúdos digitais: músicas, audiolivros, toques para celulares e vídeos. À diferença das empresas que revendem conteúdos digitais online, a Fun Station oferece um sistema que permite ao consumidor obter o produto sem a necessidade de conexão com alguma rede digital. A central de cada máquina armazena um conjunto de arquivos digitais, oferecendo-os ao consumidor que precisaria apenas conectar seu próprio reprodutor móvel (pendrive, reprodutores de mp3 ou mp4, telefones celulares, notebooks, etc.) para acessar o produto. Pensando na facilidade da transação comercial, desenvolveu-se um sistema de pagamento pelo serviço similar ao utilizado pelas operadoras de telefonia celular para 
contas de linhas de pré-pago. O consumidor pode adquirir funcards de distintos valores (cartões em que consta uma senha pessoal) nos lugares em que está alojada a máquina. O objetivo deste tipo de pagamento é evitar que o usuário perca tempo ou se sinta inseguro para comprar ao precisar repassar dados pessoais (conta de banco, cartão de crédito ou endereço eletrônico) para uma máquina exposta em lugares públicos.

Assim, a Fun Station também descentraliza suas atividades, apostando em um público que está em pleno trânsito pela cidade (casa-trabalho-escola/faculdade-casa), que possui equipamentos móveis reprodutores de arquivos digitais, mas que esbarra em obstáculos como a falta de acesso à conexão de banda larga para consumir conteúdos digitais.

\section{Bolacha Discos}

A Bolacha Discos ${ }^{10}$ é um selo que desenvolve novas estratégias de venda de seu catálogo apostando na sinergia entre distintos suportes e concertos ao vivo. A empresa foi fundada em 2006, na cidade do Rio de Janeiro, por Bernardo Palmeira (músico com passagem por gravadoras como Warner, Sony-BMG e Universal) e Carolina Monte, com o objetivo de lançar os discos de suas próprias bandas. Logo, esta cede seu lugar a Paulo Monte (ex-funcionário das gravadoras Warner e Universal). Hoje, a companhia emprega apenas seus dois empresários.

A Bolacha Discos se assemelha a um selo discográfico tradicional, trabalhando com artistas iniciantes e estratégias especializadas de marketing de bandas. Contudo, difere em aspectos importantes. Em primeiro lugar, não contrata artistas, mas é contratada para realizar "parcerias" em um determinado projeto, seja gravação seja distribuição de discos. Em segundo, utiliza como produto uma tecnologia de gravação sonora sobre suporte físico, o chamado disco semimetalizado (SMD). Apesar de ser uma tecnologia similar à do $\mathrm{CD}$, seu processo de metalização possibilita manter a qualidade da gravação, diminuindo em $80 \%$ o preço do produto final. No Brasil, o contrato com a empresa prestadora do serviço estipula que os discos devem ser vendidos a cinco reais (um CD é vendido em loja por 30 reais).

É interessante notar que a Bolacha Discos prioriza a expansão das redes de consumidores através de seus artistas. Seu objetivo é reunir o maior número de consumidores potenciais para quem possa oferecer seus produtos. Inclusive, conforme explicitado em entrevista, as bandas com que a Bolacha Discos trabalha são as que desenvolvem suas redes de fãs - daí seu catálogo não se organizar por gêneros musicais, mas artistas. 
O aumento das redes de consumidores visa à diversificação de produtos. Na medida em que se alcança uma massa crítica de potenciais compradores, é possível lhes ofertar produtos distintos com variados preços, ampliando as fontes de renda da companhia. Uma primeira experiência nesse sentido é a parceira que a Bolacha Discos estabeleceu com 1Download ${ }^{11}$, empresa que disponibiliza online catálogos dos artistas do selo para download. Os arquivos são acessados através da inserção de um código pessoal que se revela em cartões entregues gratuitamente ou vendidos aos consumidores. Uma segunda experiência da diversificação é a fabricação de discos em vinil. Os empresários da Bolacha Discos estabeleceram contato com a GZ Digital Media ${ }^{12}$, uma das últimas fábricas de discos do mundo, sediada na República Tcheca. Assim, o consumidor que assiste ao concerto pode baixar o disco pela Internet ou comprá-lo em SMD ou, se preferir, em vinil.

\section{Novos intermediários no entorno digital}

Ainda que sucintas, a descrição desses quatro casos ajuda a revelar interessantes características comuns às quatro empresas. Todas comercializam conteúdos musicais que não produzem. Sua função é obter licenças das obras gravadas por artistas ou gravadoras para distribuir a outras companhias (portais de internet ou companhias de telefonia celular) ou vender diretamente aos consumidores finais. Neste sentido, é inegável seu caráter de prestadores de serviços, o que as qualifica como novos intermediáriospróprios do entorno digital. Se no começo das redes digitais de comunicação celebrava-se o fim da intermediação - isto é, o fim de agentes que distribuíam os produtos físicos e a consequente possibilidade de contato direto entre produtores e consumidores como novidade revolucionária do mercado cultural digitalizado, os casos estudados revelam que há novas formas e diferentes graus de mediação nas relações de produção dos bens culturais.

Nesse sentido, as licenças de comercialização das obras musicais que uma empresa possa conseguir se tornam elementos decisivos para seu desenvolvimento. São tais conteúdos licenciados para exploração comercial em um determinado mercado (espaço geográfico e/ou suporte) durante um período específico de tempo que conformam os catálogos, mais ou menos atrativos, desses novos intermediários. É o apelo desses catálogos, por sua vez, que condiciona estratégias comerciais adotadas pelas empresas, segmentos de mercado que exploram diretamente, serviços prestados aterceiros que podemoferecer, entre outros aspectos que definem sua posição na cadeia 
produtiva da indústria fonográfica. Assim, a função da produção perde importância frente à gestão de licenças e a distribuição das obras.

Note-se que, entre os casos analisados, a iMusica se destaca não apenas por oferecer um catálogo com mais de dois milhões de fonogramas como também, e principalmente, por teras permissões de exploração comercial dos conteúdos mais importantes de gravadoras, as multinacionais Universal, Sony-BMG, Warner e EMI. É esta atrativa oferta de produtos que lhe permite alcançar tanto consumidores finais quanto estabelecer acordos comerciais com outros intermediários para serviços distintos - e, assim, pode-se afirmar que este tipo de empresa desempenha uma intermediação "complexa", o que deixa evidente o lugar privilegiado que a companhia ocupa na cadeia de agentes intermediários.

A certa distância da iMusica, mas desempenhando o mesmo papel, está a Fun Station. Este peculiar projeto conta com um catálogo de 300 mil fonogramas, nutrido por acordos alcançados com a gravadora multinacional Warner Music e destacados selos nacionais, como a Biscoito Fino. Com uma participação tímida no mercado de telefonia celular (vende apenas ringtones), a empresa concentra-se em um tipo de consumidor que possui e utiliza com frequência reprodutores digitais, porém não possui fácil acesso aos conteúdos digitais. A estratégia elaborada por esta firma, pois, visa atender uma parcela pouco observada do mercado digital, isto é, o de grupos que ou estão off-line ou restritamente online, e porque planeja expandir suas atividades tanto em nível local quanto, ainda que em menor escala, internacional. Dessa forma, iMusica e Fun Station não se colocam como competidores, mas como empresas que exploram segmentos de mercado distintos e até mesmo complementares.

Por sua vez, as microempresas Trevo Digital e Bolacha Discos contam com catálogos reduzidos, alimentados majoritariamente por artistas locais que autoeditam seus trabalhos fonográficos. Devido a seu capital e estrutura, além da referida natureza de seus catálogos, ambas desenvolvem estratégias nas quais figuram como ferramentas decisivas as suas páginas na internet e o uso de redes sociais para fazer conhecer seus produtos, serviços e marcas. Um dos objetivos dessa intensa utilização das possibilidades da internet é desenvolver redes de consumidores, aproveitando-se das externalidades positivas das redes (Herscovici, 2008; Shapiro; Varian, 1999), isto é, tendo seus artistas contratantes e fãs funcionando como agentes ampliadores de mercado, aumentam - a baixo custo - as possibilidades de comercialização de seus produtos. Por isto, por exemplo, Bolacha Discos utiliza o espaço da rede social MySpace como sua plataforma de acesso ao mercado. Esta 
presença em uma página virtual cujo fim é o desenvolvimento de redes de usuários potencializa sua própria força promocional e comercial em escala internacional - o que se complementa com uma atuação local em concertos dos quais participam seus artistas contratantes.

Os casos de Trevo Digital e Bolacha Discos caracterizamum tipo de intermediação que, enfim, poderíamos qualificar de "simples" - se comparada à complexa cadeia de intermediáriosem que está inserida iMusica, por exemplo.Ambas as microempresas se posicionam entre a produção realizada por artistas locais e a distribuição final dos fonogramas, optando por utilizar espaços e ferramentas virtuais e físicas (concertos) para promover e vender seus respectivos acervos.

\section{Considerações finais}

O estudo desses quatro novos empreendimentos nos permite destacar importantes características do atual mercado fonográfico brasileiro, além de sugerir interessantes hipóteses para trabalhos futuros.

Primeiramente, comprovou-se que há no mercado digital de música no Brasil agentes intermediários que oferecem conteúdos musicais em distintosformatos, suportes e sob diferentes condições de comercialização.Essas novas firmas se posicionam em diferentes espaços no interior de uma cadeia produtiva com sucessivos elos. O lugar que ocupa cada firma nesse processo depende, em larga medida, dos recursos econômicos e institucionais que possui. Assim, algumas companhias conseguem desenvolver um trabalho de mediação entre artistas e gravadoras multinacionais ou nacionais com empresas de telecomunicações, portais de internet e consumidores finais (intermediação complexa), enquanto outras se limitam a oferecer conteúdos produzidos por músicos locais diretamente a seu público final (intermediação simples).

Em segundo lugar, a obtenção de licenças para administrar os conteúdos musicais se converte em vetor significativo de diferenciação entre os novos intermediários. Aqueles que acessam os repertórios mais valiosos (que contam com artistas com alta capacidade de atrair consumidores) apresentam claras vantagens em relação aos que se restringem aos conteúdos provenientes de pequenas gravadoras ou artistas que lançam seu próprio trabalho. $O$ fato é que os tipos de serviços oferecidos, as estratégias empregadas e ferramentas utilizadas, além da escala e segmentos de mercado em que trabalham tais firmas, estão diretamente relacionados com sua capacidade de firmar contratos com aqueles agentes que controlam as licenças das obras. Tendo isto em conta, 
torna-se plausível sugerir quese configura uma nova divisão do trabalho no mercado digital de fonogramas, sendo a obtenção de licenças para a distribuição e gestão das obras musicais um aspecto determinante para o desenvolvimento de uma companhia.

Não há dúvidas, porém, de que são essas novas empresas os agentes que inovam e exploram o entorno digital, apontando caminhos a serem experimentados por outras firmas. Não sendo a gravação sonora uma função que lhes cabe, podem concentrar-se nos serviços de distribuição e venda de conteúdos, inovando constantemente em busca da ampliação de mercados. Neste sentido, desenvolvem estratégias de inserção no mercado fonográfico digital considerando tanto as características do público brasileiro (alto índice de uso de telefones celulares, baixo acesso à internet de banda larga, alta frequência aos concertos ao vivo, uso constante de redes sociais) quanto as possibilidades comunicacionais e econômicasda internet, como as redes MySpace, Youtube ou Facebook.

Resta, contudo, uma pergunta: quais são os efeitos desse cenário para a diversidade musical brasileira? Este estudo não apresenta uma resposta a tal indagação, mas sugere um quadro a se observar. Ainda que todas as empresas estudadas trabalhem com artistas locais e gravadoras nacionais independentes, a existência de um mercado no qual há distintos graus de intermediação e no qual os catálogos das gravadoras se tornam um elemento de poder de controlar e dispor sobre os conteúdos digitais, torna-se prudente rastrear possíveis novas barreiras e também potencialidades de acesso de artistas locais ao mercado consumidor final. Apenas assim se poderá ter uma noção mais exata das consequências desses novos negócios sobre a diversidade musical do mercado fonográfico brasileiro.

\section{NOTAS}

1 Este artigo deriva do texto "A procura de novos negócios fonográficos: estratégias dos empreendedores brasileiros no mercado de música", trabalho apresentado ao Grupo de Trabalho "Economia política e políticas da comunicação", do XIX Encontro da Compós, na PUC, Rio de Janeiro, RJ, em junho de 2010. Os autores gostariam de agradecer o apoio recebido da Agencia Espanhola de Cooperação Internacional para o Desenvolvimento (AECID, PCI Ibero-América, código: C/016896/08), da Coordenação de Aperfeiçoamento de Pessoal de Nível Superior (CAPES), do Departamento de Jornalismo e Comunicação Audiovisual da Universidade Carlos III de Madri (UC3M) e do Programa de PósGraduação da Escola de Comunicação da Universidade Federal do Rio de Janeiro (UFRJ). 
2 Apesar desse crescimento, os resultados parecem demasiado tímidos para compensar o déficit do mercado de fonogramas físicos. Afinal, o mercado para conteúdos digitais no Brasil é limitado. Segundo a pesquisa publicada pelo Comitê Gestor da Internet (2008, p. 45-47), o custo dos computadores, da conexão à internet e dos serviços associados continua sendo um significativo impedimento para o pleno acesso da maioria da população aos conteúdos digitais: $75 \%$ dos entrevistados não possuem computador em sua residência e $54 \%$ não tem acesso à internet.

3 Trata-se, aqui, da primeira definição de Schumpeter (1982) para o "empresário", que é o agente diferenciado que introduz uma inovação (que pode ser a introdução de um novo bem, a descoberta de um novo método de produção ou de comercialização de mercadorias ou a conquista de novas fontes de matérias-primas) rompendo com o equilíbrio de um mercado e iniciando um processo de completa transformação.

4 As entrevistas foram realizadas com: Paulo Lima da iMusica, 30/09/2009; Felippe Llerena da iMusica, 30/09/2009; Luiz Eduardo do Trevo Digital, 06/10/2009; Bruno De Marchi da Fun Station, 15/10/2009; e Paulo Monte da Bolacha Discos, $21 / 10 / 2009$

$5<$ www.imusica.com.br>

$6<$ www.trevodigital.com.br/>

$7<$ http://www.myspace.com/trevodigital $>$

$8<$ www.trevobox.com.br>

$9<$ www.funstation.com.br/>

${ }^{10}<$ wWw.myspace.com/bolachadiscos $>$

$11<$ www.1download.com.br>

$12<$ www.gzdm.cz $>$

\section{REFERÊNCIAS}

ALBORNOZ, Luis A. Digitalização e sociedade: o caso do setor musical. Conferência inaugural do II Congresso da União Latina de Economia Política da Informação, a Comunicação e a Cultura, seção Brasil (ULEPICC-Brasil), Universidade Estadual Paulista “Júlio de Mesquita Filho", São Paulo, 13-15 de agosto de 2008.

ALBORNOZ, Luis A.; HERSCHMANN, Micael. La industria de la música en transición. Tenerife: Cabildo de Tenerife, 2010. (no prelo).

ASSOCIAÇÃO BRASILEIRA DE PRODUTORES DE DISCOS. Mercado brasileiro de música 2009. Rio de Janeiro: ABPD, 2009. Disponível em: <http://www.abpd.org.br/downloads/Mercado_Fonografico_BR_15abril09.pdf>. Acesso em: 05 fev. 2010.

BUSTAMANTE, Enrique (Coord.). Hacia un nuevo sistema de comunicación: las industrias culturales en la era digital. Barcelona: Gedisa, 2007. 
COMITÊ GESTOR DA INTERNET NO BRASIL. Pesquisa sobre o uso das tecnologias da informação e da comunicação no Brasil: TIC domicílios e TIC empresas 2008. São Paulo: CGI.br, 2009. Disponível em: <http://www.cetic.br/tic/2009/ index.htm>. Acesso em: 05 fev. 2010.

DIAS, Márcia T. Os donos da voz: indústria fonográfica brasileira e mundialização da cultura. São Paulo: Boitempo, 2000.

HERSCHMANN, Micael. Alguns apontamentos sobre a reestruturação da indústria da música. In:

HERSCHMANN, Micael; FREIRE FILHO, J. (org.). Novos rumos da cultura da mídia. Rio de Janeiro: Mauad X, 2006. p. 161-188.

Lapa: cidade da música. Rio de Janeiro: Mauad X, 2007.

HERSCOVICI, Alain. Redes eletrônicas e economia digital: economia da dádiva ou novas estratégias concorrenciais? Trabalho apresentado ao Grupo de Trabalho "Economia política da comunicação e políticas da comunicação", do XVII Encontro da Compós, na UNIP, São Paulo, junho de 2008.

INTERNATIONAL FEDERATION OF THE PHONOGRAPHIC INDUSTRY. Digital musicreport2010. Londres. Disponível em: <http://www.abpd.org.br/downloads/DMR2010_UK_JAN2010.pdf>. Acesso em: 05 fev. 2010.

MIDANI, André. Música, ídolos e poder: do vinil ao download. Rio de Janeiro: Nova Fronteira, 2008.

MORELLI, Rita C. L. Indústria fonográfica: um estudo antropológico. 2. ed. Campinas: Ed. Unicamp, 2009.

NAPOLITANO, Marcos. Seguindo a canção: engajamento político e indústria cultural na MPB 1959-1969. São Paulo: Annablume/Fapesp, 2001.

PRESTES FILHO, Luís C. (Coord.). Cadeia produtiva da economia da música. Rio de Janeiro: Instituto Gênesis/PUC-RJ, 2005.

SCHUMPETER, Joseph A. A teoria do desenvolvimento econômico. São Paulo: Abril Cultural, 1982.

SHAPIRO, Carl; VARIAN, Hai R. Information rules: a strategic guide to network economy. Cambridge, Massachusetts: Harvard Business School Press, 1999. 